\title{
Assessing communication skills during OSCE: need for integrated psychometric approaches
}

\author{
Giovanni Piumatti ${ }^{1,2,3^{*}}$ (D), Bernard Cerutti ${ }^{3}$ and Noëlle Junod Perron ${ }^{3,4}$
}

\begin{abstract}
Background: Physicians' communication skills (CS) are known to significantly affect the quality of health care. Communication skills training programs are part of most undergraduate medical curricula and are usually assessed in Objective Structured Clinical Examinations (OSCE) throughout the curriculum. The adoption of reliable measurement instruments is thus essential to evaluate such skills.

Methods: Using Exploratory Factor Analysis (EFA), Multi-Group Confirmatory Factor Analysis (MGCFA) and Item Response Theory analysis (IRT) the current retrospective study tested the factorial validity and reliability of a fouritem global rating scale developed by Hodges and Mcllroy to measure CS among 296 third- and fourth-year medical students at the Faculty of Medicine in Geneva, Switzerland, during OSCEs.

Results: EFA results at each station showed good reliability scores. However, measurement invariance assessments through MGCFA across different stations (i.e., same students undergoing six or three stations) and across different groups of stations (i.e., different students undergoing groups of six or three stations) were not satisfactory, failing to meet the minimum requirements to establish measurement invariance and thus possibly affecting reliable comparisons between students' communication scores across stations. IRT revealed that the four communication items provided overlapping information focusing especially on high levels of the communication spectrum.

Conclusions: Using this four-item set in its current form it may be difficult to adequately differentiate between students who are poor in CS from those who perform better. Future directions in best-practices to assess CS among medical students in the context of OSCE may thus focus on (1) training examiners so to obtain scores that are more coherent across stations; and (2) evaluating items in terms of their ability to cover a wider spectrum of medical students' CS. In this respect, IRT can prove to be very useful for the continuous evaluation of CS measurement instruments in performance-based assessments.
\end{abstract}

Keywords: Communication assessment, OSCE, Item response theory, Measurement invariance

\footnotetext{
* Correspondence: giovanni.piumatti@hcuge.ch

'Division of Primary Care, Population Epidemiology Unit, Geneva University Hospitals, Geneva, Switzerland

${ }^{2}$ Institute of Public Health, Faculty of BioMedical Sciences, Università della Svizzera Italiana, Lugano, Switzerland

Full list of author information is available at the end of the article
}

(c) The Author(s). 2021 Open Access This article is licensed under a Creative Commons Attribution 4.0 International License, which permits use, sharing, adaptation, distribution and reproduction in any medium or format, as long as you give appropriate credit to the original author(s) and the source, provide a link to the Creative Commons licence, and indicate if changes were made. The images or other third party material in this article are included in the article's Creative Commons licence, unless indicated otherwise in a credit line to the material. If material is not included in the article's Creative Commons licence and your intended use is not permitted by statutory regulation or exceeds the permitted use, you will need to obtain permission directly from the copyright holder. To view a copy of this licence, visit http://creativecommons.org/licenses/by/4.0/ The Creative Commons Public Domain Dedication waiver (http://creativecommons.org/publicdomain/zero/1.0/) applies to the data made available in this article, unless otherwise stated in a credit line to the data. 


\section{Background}

Physicians' communication skills (CS) are positively associated with a variety of health care outcomes, including patients' physical and emotional health, pain control and better doctor-patient relationships [1-3]. CS are therefore recognized as crucial competencies for medical students and key components of medical practice [4-6]. Accordingly, nowadays most medical curricula include a longitudinal communication training track [7-9].

The Objective Structured Clinical Examination (OSCE) is a widely adopted tool by medical schools to assess CS among their students using interactions with standardized patients $[10,11]$. It consists of different stations simulating real physician-patient encounters in clinical settings. CS can be assessed by OSCE stations specifically developed to test these skills as well as in an integrated way alongside other clinical skills [12]. The validity of students' performances in CS strongly depends on the adopted measurement instrument. Two recent reviews evidenced a wide range of tools to measure medical students' CS in OSCE $[13,14]$. In addition to pointing out that such heterogeneity in measurement instruments prevents comparison across different settings, these reviews evidenced two main limitations of existing scales: the low inter-rater agreement and the lack of appropriate psychometric techniques in previous studies able to evaluate the overall validity and reliability of a scale. Since medical educators often need to evaluate students' CS several times during the overall curriculum in order to monitor individual progresses and identify those in need of remediation [15], these same limitations become even more critical when comparing students' longitudinal performances within the same institution.

As pointed out by Boon and Stewart [16], it is important that medical education educators and researchers focus on strengthening the evidence for the validity and reliability of available instruments in order to provide guidance for future assessments and to suggest how to improve existing scales. Although there is no unanimous consensus on this matter, previous researchers suggested that global rating scales for CS perform better than more complex behavioural checklists $[13,14,16,17]$. However, when adopting global rating scales to measure CS we often make a priori assumptions about the factorial structure of these scales without actually testing them $[13,14]$. In the context of OSCE, testing the validity of the factorial structure of a given global rating scale for CS means bringing evidence that this scale actually measures the same latent variable across different stations, namely CS. It also means ultimately assessing the invariance of this factorial structure across stations [18, 19]. More precisely, this implies that ideally when switching from a station to another the underlying model linking items to the latent variable is globally stable (configural invariance), the loadings (roughly speaking the contribution of every item to the CS) are stable (metric invariance), the intercepts are stable (i.e., there is no systematic response bias; scalar invariance), and the residual (i.e., the measure error) variability is also stable (strict invariance). Only by doing so we can test if we are reliably comparing scores between different stations on the basis of a derived global rating for CS. All these steps have important implications for the interpretation of CS' scores within OSCE and for any conclusions about group- and station-related differences. In fact, unless we can conclude that the assumption of measurement invariance is met, we cannot legitimately compare scores across stations for example, as well as across contexts. For any global rating scale of CS thus, this technique can be used to assess whether a specific set of items is interpreted in a conceptually similar manner across stations dealing with different clinical scenarios.

Using multi-group factorial analysis techniques, the current study tested the measurement invariance of a widely adopted global rating scale proposed by Hodges and McIlroy [20-23] to assess medical students' CS during OSCE. In addition, we further extended the psychometric assessment of this instrument into Item Response Theory analysis (IRT) [24]. The goal of IRT is first of all to assess the 'ability' of each item to tap into a specific portion of an underlying measure, in our case CS. Such items' ability characteristic can be described as their 'difficulty', namely how hard it is for the examinee to score higher on a specific scale, given his or her overall level along the trait measured by that scale. Thus the IRT analysis allows to single out which items are able to differentiate between examinees with different levels of CS. More specifically, IRT can highlight if the items of this specific scale by Hodges and McIlroy provides overlapping information regarding medical students' levels of CS. For example, it might happen that all items are good at differentiating between examinees with very high levels of CS and examinees with high levels, but none at differentiating between very high and low examinees for example. So, IRT would be able to point out directions for future improvement of the same instrument, suggesting the exclusion of items that do not add more information, or the inclusion of new items (or adaptation of the existing ones) to cover a wider spectrum of CS.

In sum, the dual approach of measurement invariance techniques and IRT, can bring evidence to help defining best-practice instruments, or suggesting modification of the existing ones, to measure CS during OSCE.

\section{Methods}

\section{Sample and measures}

This study was conducted at the Faculty of Medicine in Geneva, Switzerland, which offers a six-year curriculum to approximately 160 students per year. All the students 
take simultaneously a clinical skill exam of three OSCE stations of $18 \mathrm{~min}$ at the end of the third year, which focuses on history taking, physical exam, and a short explanation. Students also take an internal medicine and primary care medicine exam of six OSCE stations of 13 min, either at the mid or at the end of the fourth year, depending on the distribution of the clinical rotations. The clerkship in each discipline has a duration of two months. The stations (three in internal medicine and three in primary care) are integrative, and usually focus on history taking, physical exam, and case management. During the 2017/2018 academic year a global rating scale for CS [20] was added to the checklists of every station. Examiners were not formally trained to use this scale during OSCE at the Faculty of Medicine in Geneva, although $40 \%$ of them $(n=43)$ received formal training for its adoption during the Federal Licensing Examination in Switzerland. The scale has four dimensions measured on a $0=$ poor to $4=$ excellent Likert scale:

1) Respond to patient's feelings and needs: Respond in a perspicacious and adequate way to solicitations and needs - verbal or non-verbal - of the patient.

2) Interview's structure: Recognizable, coherent and flexible interaction plan during the entire consultation; the candidate conducts the interview in a coherent way.

3) Verbal expression: He/She communicates in an appropriate way that favours the comprehension and adapts the communication to the patient; the vocabulary is adapted to the socio-cultural level, with repetitions, summaries, articulations, tone, etc.

4) Non-verbal expression: $\mathrm{He} / \mathrm{She}$ favours the relationship with the patient and his/her involvement through eye-contact, gestures, posture, interpersonal distance, pauses, etc.

In Switzerland, this scale is currently used in the context of the Federal Licensing Exam, where it showed good internal consistency among the four dimensions [25], as in other previous research within OSCE's settings [20-23]. The selection of this instrument at the Swiss national level derives from few essential considerations: 1) the state-of-the-art of instructional methods and assessments for CS across Swiss medical schools; 2) the direct use of the instrument without the need for specific training; 3 ) the broad coverage of communication competencies being therefore applicable to different medical faculties independently by their curriculum; and 4) the ability to complete the assessment of CS in less than 2 min [25]. Nevertheless, to the best of the authors' knowledge, no study has yet evaluated the invariance of the factorial structure of this scale across stations, or applied IRT to it. For the current study, we used CS evaluation scores for 147 fourth-year students across six stations and 149 third year students across three stations, for a total of 24 stations. As part of routine quality improvement projects no administrative permission was required to access the raw data used in the study. Specifically, this study was approved by the teaching committee and the anonymised data were provided by the administration.

\section{Data analysis}

First, Exploratory Factor Analysis (EFA) with principalcomponent factor method was applied to the four-item set measuring CS in each single OSCE station. In this way we could explore the factorial structure of this instrument across different examiners' scores. The following indexes were used to determine the best factorial solution: extraction of factors with eigenvalues $>1$, total variance explained by the chosen factorial solution > $50 \%$, factor loadings $>0.30$, values from Kaiser-MeyerOlkin test (KMO) regarding the suitability of the data for factor analyses $>0.7$, significance of Bartlett's test of sphericity to test the hypothesis of the multivariate normal distribution with zero covariance of the data, and Cronbach's alphas reliability results $>0.70$ [26-28].

Subsequently, we tested the assumption of measurement invariance for this four-item set across different OSCE stations (i.e., same students undergoing six or three stations) and across different groups of OSCE stations (i.e., different students undergoing groups of six or three stations) using Multi-Group Confirmatory Factor Analysis (MGCFA) with Maximum Likelihood (ML) estimation method. In order to test for measurement invariance across different groups of OSCE stations, we calculated students' rounded mean scores for each item across stations so that each item had a single derived average score from different stations' evaluations. Invariance testing followed a series of hierarchical models each adding an increasing number of constraints across groups [18]. First, it was tested whether the same parameters existed in the fourth-year students' group undertaking six stations and in the third-year students' groups undertaking three stations (configural invariance, that is the pattern of factor relationships are identical across groups). Then factor loadings were constrained to be equal across groups (metric invariance, that is the coefficient allowing to estimate the latent variable from the original score are identical), followed by item intercepts (scalar invariance, that is no systematic bias if one group is assessed rather than another), and residual variances (strict invariance, that is the error variability is the same whatever the group who is assessed). Model fit was evaluated using (1) $\chi^{2}$ goodness-of-fit, (2) Root Mean Square Error of Approximation (RMSEA; with values $\leq 0.08$ being indicative of acceptable fit to the data), and (3) 
Comparative Fit Index (CFI; $\geq 0.9$ ). Following recommendation from Chen [29], for testing configural invariance, a change of $\leq-0.005$ in CFI, supplemented by a change of $\geq 0.01$ in RMSEA would indicate noninvariance; for testing metric or scalar invariance, a change of $\geq-0.005$ in CFI, supplemented by a change of $\geq 0.01$ in RMSEA would indicate noninvariance.

Finally, IRT was used to examine single items' properties and overall reliability of the scale on the whole sample. This technique allows to determine at which CS levels students are more likely to score at a given scale point. To do so, we used the items' rounded mean scores for each student based on the scores from different stations that he or she had taken. Since all obtained rounded scores ranged between 2 and 4 with very small proportions of students who received a 2 on any given item (between 2 and 5\%), we recoded every item into binary scores: 2 and 3 equal to 0 (i.e., failure) and 4 equal to 1 (i.e., success). This had implication for the type of IRT model to adopt, since with ordinal items we could have opted for a graded response model [30]. However, the very small percentage of individuals with averaged scores equal to 2 would have made inappropriate this approach for about $95 \%$ of our sample for which scores where either 3 or 4 . Instead, working with binary items we tested two different IRT models: a 1-parameter model (1-PL), often called Rasch model, differentiating items based solely on their 'difficulty' (i.e., the parameter indicating at what level of the measured underlying trait a subject has to be to score higher on a specific item); and a 2-parameter model (2-PL) based on both item difficulty and item discrimination representing the extent to which an item discriminates between different trait levels (higher values indicating a stronger association with the measured construct) $[31,32]$. We used a likelihood-ratio test to determine which one of these two models better explained our data. Items' information functions were graphically plotted for interpretation along with the conditional standard errors and test information function for the four-item scale as a whole to evaluate the fit of the model to the data.

Analyses were conducted using Stata (version 15; StataCorp LP, College Station, TX, USA) and AMOS software (version 25.0; IBM Corp., Chicago, IL, USA).

\section{Results}

Absolute values of skewness and kurtosis ranged respectively from 0 to 1.86 , and from 1.09 to 9.72 , suggesting that items' scores were reasonably normally distributed (see Table A1 in the Appendix) [33]. The overall mean across all stations and students were respectively $3.07(81.3 \%$ of scoring 3 or 4$)$ for Item 1 , $3.17(83.7 \%$ of 3 or 4$)$ for Item $2,3.24$ ( $87.4 \%$ of 3 or 4$)$ for Item 3 , and $3.16(83.7 \%$ of 3 or 4$)$ for Item 4 .
Correlations between the four items ranged between 0.20 and 0.84 across all stations.

Results from EFA suggested that across all stations the one-factor solution appeared to be the most appropriate to synthesize the four global rating items, with factor loadings ranging from 0.56 to 0.94 and Cronbach's alphas ranging from 0.69 to 0.92 (Table 1). Results of the MGCFA are summarised in Table 2. Only the observations from the first group of students can be considered reasonably invariant across stations, although the one-factor solution for $\mathrm{CS}$ in this group only reached the threshold for partial invariance as described by Byrne et al. [34]. Reading from the results reported in Table A2, also in the case of measurement invariance testing across different groups of OSCE stations (i.e., different students undergoing groups of six or three stations) the minimum requirement for measurement invariance was not reached. More specifically, we cannot safely assume that the calibration of these items is similar across stations. This implies that the meaning of the obtained score from this scale is not the same across stations [18].

There was no evidence of a difference between the two-parameter IRT model and the one-parameter model $\left(\chi^{2}=3.30, d f=3\right.$, likelihood ratio test $\left.p=0.348\right)$. This suggested that there is no difference in how discriminating the four items are, but the items can be differentiated based solely on their difficulty. Item 1 (Response to the patient's feeling and need) appeared to be the most difficult (see Table 3 and Fig. 1). An examinee must have a latent score (i.e., Theta) equal to 1.28 to get a $50 \%$ chance to obtain the highest mark for this item. Theta represents the true latent score in CS that has been standardized on a scale from -4 to 4 , although it is unlikely to find somebody scoring at those extremes. Accordingly, a student who has a very low ability in CS, say Theta $=-2$, would have a very small probability of getting a high score on this item. Conversely, a student with high ability in CS, say Theta $=2$, would most certainly get a high score on this item. Figure 1 shows the amount of information brought by each item. Items 2, 3 and 4 appear to provide overlapping information and are thus redundant (items 2 and 4 in particular). Figure 2 depicts the conditional standard errors and test information function for the four-item communication scale. This battery of items seems to have low levels of standard error and concurrently a high level of provided information approximately only for latent scores ranging from 0 to 2 .

\section{Discussion}

This study tested the factorial validity and reliability of a four-item global scale to assess medical students' CS in OSCE settings. When considering each specific OSCE 
Table 1 Results of exploratory factor analyses applied to the four-item communication scale by OSCE stations: Standardized results from one-factor solutions are shown

\begin{tabular}{|c|c|c|c|c|c|c|c|c|}
\hline \multirow[t]{3}{*}{ Station } & \multicolumn{4}{|c|}{ One-factor } & \multirow{3}{*}{$\begin{array}{l}\text { Variance } \\
\text { explained } \\
\text { a }\end{array}$} & \multirow[t]{3}{*}{ KMO } & \multirow{3}{*}{$\begin{array}{l}\text { Bartlett's } \\
p\end{array}$} & \multirow[t]{3}{*}{$a$} \\
\hline & Item 1 & Item 2 & Item 3 & Item 4 & & & & \\
\hline & $\beta$ & $\beta$ & $\beta$ & $\beta$ & & & & \\
\hline \multicolumn{9}{|c|}{ Group $1(n=35)$} \\
\hline Station 1 & 0.841 & 0.846 & 0.904 & 0.864 & $75 \%$ & 0.826 & $<0.001$ & 0.880 \\
\hline Station 2 & 0.879 & 0.680 & 0.747 & 0.935 & $67 \%$ & 0.716 & $<0.001$ & 0.827 \\
\hline Station 3 & 0.787 & 0.741 & 0.789 & 0.596 & $54 \%$ & 0.719 & 0.001 & 0.688 \\
\hline Station 4 & 0.922 & 0.853 & 0.866 & 0.848 & $76 \%$ & 0.747 & $<0.001$ & 0.894 \\
\hline Station 5 & 0.844 & 0.749 & 0.826 & 0.816 & $66 \%$ & 0.667 & $<0.001$ & 0.824 \\
\hline Station 6 & 0.844 & 0.903 & 0.684 & 0.906 & $70 \%$ & 0.797 & $<0.001$ & 0.854 \\
\hline \multicolumn{9}{|c|}{ Group $2(n=51)$} \\
\hline Station 1 & 0.857 & 0.562 & 0.914 & 0.914 & $68 \%$ & 0.768 & $<0.001$ & 0.828 \\
\hline Station 2 & 0.828 & 0.831 & 0.879 & 0.868 & $73 \%$ & 0.800 & $<0.001$ & 0.873 \\
\hline Station 3 & 0.874 & 0.854 & 0.929 & 0.933 & $81 \%$ & 0.845 & $<0.001$ & 0.916 \\
\hline Station 4 & 0.860 & 0.661 & 0.829 & 0.872 & $66 \%$ & 0.786 & $<0.001$ & 0.818 \\
\hline Station 5 & 0.760 & 0.761 & 0.912 & 0.829 & $67 \%$ & 0.681 & $<0.001$ & 0.820 \\
\hline Station 6 & 0.711 & 0.682 & 0.808 & 0.737 & $54 \%$ & 0.608 & $<0.001$ & 0.711 \\
\hline \multicolumn{9}{|c|}{ Group $3(n=61)$} \\
\hline Station 1 & 0.819 & 0.708 & 0.903 & 0.861 & $68 \%$ & 0.778 & $<0.001$ & 0.841 \\
\hline Station 2 & 0.857 & 0.777 & 0.829 & 0.786 & $66 \%$ & 0.771 & $<0.001$ & 0.825 \\
\hline Station 3 & 0.723 & 0.695 & 0.819 & 0.852 & $60 \%$ & 0.763 & $<0.001$ & 0.775 \\
\hline Station 4 & 0.770 & 0.625 & 0.789 & 0.797 & $56 \%$ & 0.662 & $<0.001$ & 0.730 \\
\hline Station 5 & 0.706 & 0.800 & 0.858 & 0.823 & $64 \%$ & 0.704 & $<0.001$ & 0.808 \\
\hline Station 6 & 0.804 & 0.782 & 0.836 & 0.820 & $66 \%$ & 0.808 & $<0.001$ & 0.821 \\
\hline \multicolumn{9}{|c|}{ Group $4(n=89)$} \\
\hline Station 1 & 0.866 & 0.809 & 0.859 & 0.846 & $71 \%$ & 0.823 & $<0.001$ & 0.865 \\
\hline Station 2 & 0.848 & 0.826 & 0.874 & 0.910 & $75 \%$ & 0.796 & $<0.001$ & 0.885 \\
\hline Station 3 & 0.900 & 0.697 & 0.836 & 0.846 & $68 \%$ & 0.767 & $<0.001$ & 0.838 \\
\hline \multicolumn{9}{|c|}{ Group $5(n=60)$} \\
\hline Station 1 & 0.813 & 0.709 & 0.761 & 0.874 & $63 \%$ & 0.724 & $<0.001$ & 0.798 \\
\hline Station 2 & 0.758 & 0.846 & 0.825 & 0.857 & $68 \%$ & 0.774 & $<0.001$ & 0.838 \\
\hline Station 3 & 0.777 & 0.841 & 0.874 & 0.801 & $68 \%$ & 0.803 & $<0.001$ & 0.842 \\
\hline
\end{tabular}

Notes. ${ }^{a}$ Variance explained by one single factor with eigenvalue $>1 ; \beta$ : Standardized factor loadings; KMO: Kaiser-Meyer-Olkin; $\alpha$ : Cronbach's alpha; Item 1: Respond to patient's feelings and needs: respond in a perspicacious and adequate way to solicitations and needs - verbal or non-verbal - of the patient; Item 2 : Interview's structure: recognizable, coherent and flexible interaction plan during the entire consultation; the candidate conducts the interview in a coherent way Item 3: Verbal expression: he/she communicates in an appropriate way that favours the comprehension and adapts the communication to the patient; the vocabulary is adapted to the socio-cultural level, with repetitions, summaries, articulations, tone, etc.; Item 4: Non-verbal expression: he/she favours the relationship with the patient and his/her involvement trough eye-contact, gestures, posture, interpersonal distance, pauses, etc.

station separately, it appears that this scale provides reliable information about students' CS. However, the assumption of measurement invariance across stations was clearly not met, suggesting that there is likely to be both little agreement between different examiners and a significant interaction between the examinee and the examination settings. Thus the comparisons of students' CS across different OSCE stations is difficult. For example, it may be problematic even interpreting mean differences in CS between different stations, as well as reliably comparing scores of the same students across time. Indeed, configural and metric invariances for the whole factor structure and for each factor loading are crucial for the interpretation of the constructs and are requisites for all other tests [18]. Based on these findings, we cannot ensure that this four-item communication scale is invariant across stations, not even when students are evaluated along three instead of six OSCE. This 
Table 2 Results of the four-item communication scale measurement invariance testing across OSCE stations

\begin{tabular}{|c|c|c|c|c|c|c|c|c|c|}
\hline Model & $x^{2}$ & $d f$ & RMSEA (90\% Cls) & CFI & $\Delta x^{2}$ & $\Delta d f$ & $\triangle$ RMSEA & $\Delta \mathrm{CFI}$ & Comparison \\
\hline \multicolumn{10}{|l|}{ Group $1(n=35)$} \\
\hline Model 1. Configural invariance & $23.66^{*}$ & 12 & $0.069(0.025,0.110)$ & 0.967 & & & & & \\
\hline Model 2. Metric invariance & $41.72^{*}$ & 27 & $0.052(0.025,0.110)$ & 0.959 & 18.06 & 15 & -0.017 & -0.008 & Model 2 vs. Model 1 \\
\hline Model 3. Scalar invariance & $73.27^{* *}$ & 47 & $0.052(0.027,0.075)$ & 0.926 & $31.55^{*}$ & 20 & 0.000 & -0.033 & Model 3 vs. Model 2 \\
\hline Model 4. Strict invariance & $159.89^{* * *}$ & 67 & $0.082(0.066,0.099)$ & 0.739 & $86.62^{* * *}$ & 20 & 0.030 & -0.187 & Model 4 vs. Model 3 \\
\hline \multicolumn{10}{|l|}{ Group $2(n=51)$} \\
\hline Model 1. Configural invariance & $24.72^{*}$ & 12 & $0.059(0.025,0.093)$ & 0.977 & & & & & \\
\hline Model 2. Metric invariance & $54.18^{* *}$ & 27 & $0.058(0.035,0.080)$ & 0.950 & $29.46^{*}$ & 15 & -0.001 & -0.027 & Model 2 vs. Model \\
\hline Model 3. Scalar invariance & $124.41^{* * *}$ & 47 & $0.074(0.058,0.090)$ & 0.859 & $70.23^{* * *}$ & 20 & 0.016 & -0.091 & Model 3 vs. Model 2 \\
\hline Model 4. Strict invariance & $150.36^{* * *}$ & 67 & $0.064(0.051,0.078)$ & 0.848 & 25.95 & 20 & -0.010 & -0.011 & Model 4 vs. Model 3 \\
\hline \multicolumn{10}{|l|}{ Group $3(n=61)$} \\
\hline Model 1. Configural invariance & $22.48^{*}$ & 12 & $0.049(0.014,0.080)$ & 0.978 & & & & & \\
\hline Model 2. Metric invariance & $41.61^{*}$ & 27 & $0.039(0.010,0.061)$ & 0.969 & 19.13 & 15 & -0.010 & -0.009 & Model 2 vs. Model 1 \\
\hline Model 3. Scalar invariance & $105.10^{* * *}$ & 47 & $0.059(0.044,0.074)$ & 0.875 & $63.49^{* * *}$ & 20 & 0.020 & -0.094 & Model 3 vs. Model 2 \\
\hline Model 4. Strict invariance & $171.10^{* * *}$ & 67 & $0.066(0.054,0.078)$ & 0.777 & $66.00^{* * *}$ & 20 & 0.007 & -0.098 & Model 4 vs. Model 3 \\
\hline \multicolumn{10}{|l|}{ Group $4(n=89)$} \\
\hline Model 1. Configural invariance & 9.57 & 6 & $0.047(0.000,0.101)$ & 0.993 & & & & & \\
\hline Model 2. Metric invariance & $25.69^{*}$ & 12 & $0.066(0.030,0.101)$ & 0.973 & $16.12^{*}$ & 6 & 0.019 & -0.020 & Model 2 vs. Model 1 \\
\hline Model 3. Scalar invariance & $45.83^{* * *}$ & 20 & $0.070(0.043,0.097)$ & 0.950 & $20.14^{* *}$ & 8 & 0.004 & -0.023 & Model 3 vs. Model 2 \\
\hline Model 4. Strict invariance & $74.09^{* * *}$ & 28 & $0.079(0.057,0.101)$ & 0.910 & $28.26^{* * *}$ & 8 & 0.009 & -0.040 & Model 4 vs. Model 3 \\
\hline \multicolumn{10}{|l|}{ Group $5(n=60)$} \\
\hline Model 1. Configural invariance & 8.38 & 6 & $0.047(0.000,0.116)$ & 0.991 & & & & & \\
\hline Model 2. Metric invariance & $22.27^{*}$ & 12 & $0.070(0.018,0.114)$ & 0.960 & $13.89^{*}$ & 6 & 0.023 & 0.031 & Model 2 vs. Model \\
\hline Model 3. Scalar invariance & $46.17^{* * *}$ & 20 & $0.086(0.053,0.119)$ & 0.898 & $23.90^{* *}$ & 8 & 0.016 & -0.062 & Model 3 vs. Model 2 \\
\hline Model 4. Strict invariance & $53.33^{* *}$ & 28 & $0.071(0.041,0.100)$ & 0.902 & 7.16 & 8 & 0.005 & 0.004 & Model 4 vs. Model 3 \\
\hline
\end{tabular}

Notes. $X^{2}$ Chi-square goodness of fit, $d f$ degrees of freedom, RMSEA Root Mean Square Error of Approximation, $90 \%$ Cls $90 \%$ Confidence Intervals for RMSEA, CFI Comparative Fit Index, $\Delta X$ Chi-square goodness of fit difference, $\triangle d f$ degrees of freedom difference, $\triangle C F I$ CFI difference, $\triangle R M S E A$ RMSEA difference. ${ }^{*} p<.05$,

${ }^{* *} p<.01,{ }^{* * *} p<.001$. The best fitting solutions for each group are marked in bold

imposes serious challenges if we want to compare in a meaningful way CS between different simulated clinical scenarios.

Previous studies have noticed that the main sources of variance in CS scores during OSCE are related to candidates' individual characteristics such as level of training that become evident across different stations, but also to examiners' propensity to pass or fail candidates [20,35, 36]. More actions would be therefore needed to 'normalise' assessments across examiners and stations. For instance, it is advisable to revise with the examiners how to adequately use the entire 5-level Likert scale for each item. In this regard, given the

Table 3 Results of a 1-parameter (i.e., difficulty) Rasch model applied to the four-item communication scale ( $N=296)$

\begin{tabular}{|c|c|c|c|}
\hline Item & Coefficient & $\begin{array}{l}\text { Standard } \\
\text { error }\end{array}$ & $\begin{array}{l}(90 \% \\
\text { Cls) }\end{array}$ \\
\hline $\begin{array}{l}\text { 1. Respond to patient's feelings and needs: respond in a perspicacious and adequate way to solicitations and } \\
\text { needs - verbal or non-verbal - of the patient. }\end{array}$ & 1.28 & 0.12 & $\begin{array}{l}(1.08, \\
1.48)\end{array}$ \\
\hline $\begin{array}{l}\text { 2. Interview's structure: recognizable, coherent and flexible interaction plan during the entire consultation; the } \\
\text { candidate conducts the interview in a coherent way. }\end{array}$ & 0.74 & 0.09 & $\begin{array}{l}(0.59, \\
0.90)\end{array}$ \\
\hline $\begin{array}{l}\text { 3. Verbal expression: he/she communicates in an appropriate way that favours the comprehension and adapts the } \\
\text { communication to the patient; the vocabulary is adapted to the socio-cultural level, with repetitions, summaries, } \\
\text { articulations, tone, etc. }\end{array}$ & 0.56 & 0.09 & $\begin{array}{l}(0.41 \\
0.70)\end{array}$ \\
\hline $\begin{array}{l}\text { 4. Non-verbal expression: he/she favours the relationship with the patient and his/her involvement trough eye- } \\
\text { contact, gestures, posture, interpersonal distance, pauses, etc. }\end{array}$ & 0.82 & 0.10 & $\begin{array}{l}(0.66 \\
0.98)\end{array}$ \\
\hline
\end{tabular}




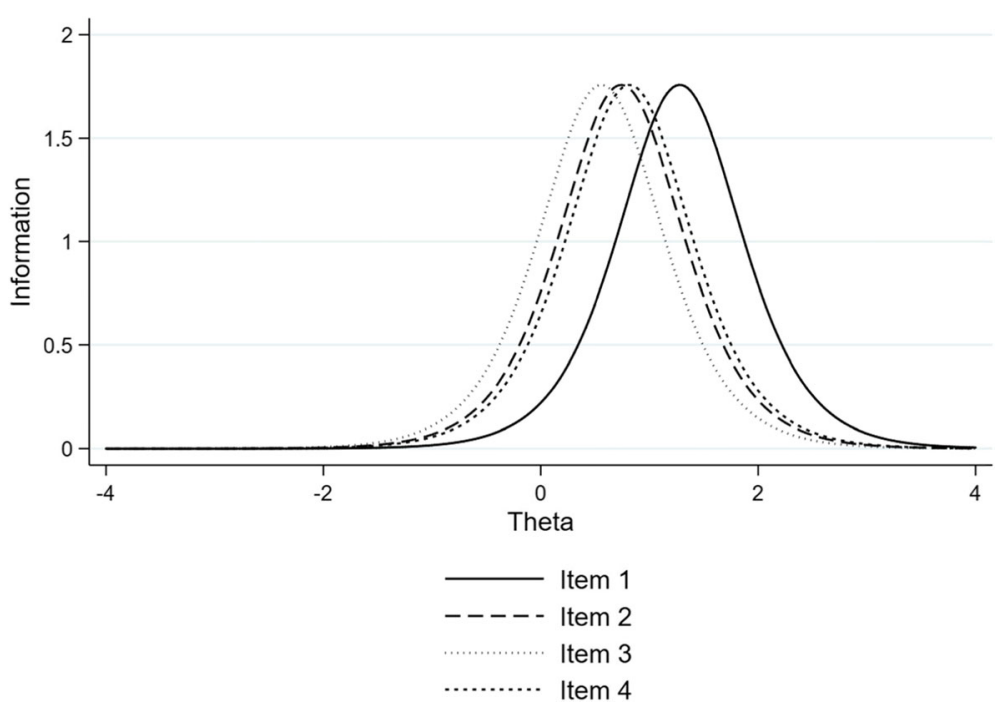

Fig. 1 Item information graph for Rasch (1-PL) analysis of four-item communication scale ( $N=296)$. Notes. Item 1: Respond to patient's feelings and needs: respond in a perspicacious and adequate way to solicitations and needs - verbal or non-verbal - of the patient; Item 2: Interview's structure: recognizable, coherent and flexible interaction plan during the entire consultation; the candidate conducts the interview in a coherent way; Item 3: Verbal expression: he/she communicates in an appropriate way that favours the comprehension and adapts the communication to the patient; the vocabulary is adapted to the socio-cultural level, with repetitions, summaries, articulations, tone, etc.; Item 4: Non-verbal expression: he/she favours the relationship with the patient and his/her involvement trough eye-contact, gestures, posture, interpersonal distance, pauses, etc.

fact that the lowest levels of the rating scale were extremely unlikely to be used, revisions of the instrument may raise the question of reducing the scoring range to binary options (e.g., pass/fail). In addition, as an alternative to a global score in CS, future adoptions of this instrument may use the scores from single items to compare students' performances between stations rather than computing a summated outcome for CS based on this four-item set.
The IRT analysis brought important evidence about how this set of items may be improved in the future, for example by elaborating items that would better discriminate between very poor and lower-average communication skilled medical students. Thus, adding new items tapping into the uncovered portion of the CS spectrum, or modifying existing ones accordingly, may help to better discriminate between students and avoid ceiling effects in the

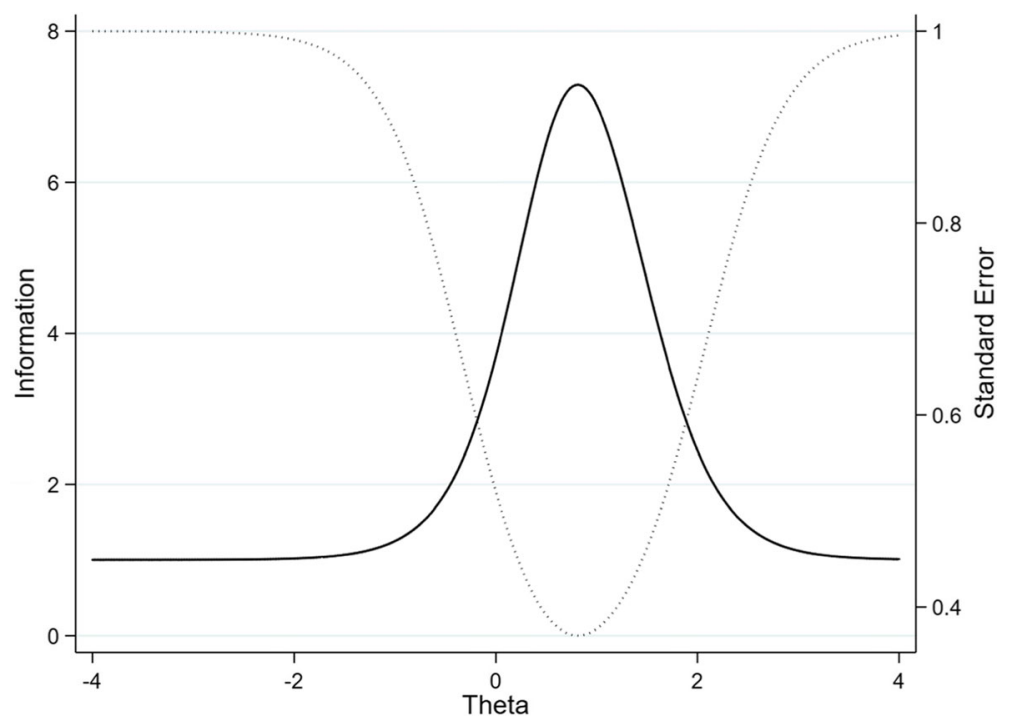

Fig. 2 Information graph showing the four-item communication scale: Test information function (solid line) and conditional standard error curve (dotted line) $(N=296)$ 
scoring system, with every student scoring high on communication. On a related note, shorter versions of this current scale should also be tested, since the two items measuring interview's structure and non-verbal expression appear to measure the same portion of the CS spectrum and are thus redundant. These results indicate that to improve the discriminative power of this scale we may want to add more items or modify existing ones so to tap into low levels of CS as in this current form we are not able to adequately differentiates between students who have low levels of CS from those who perform better.

It is also important to remind that if we interpret the poor measurement invariance performance of this global rating scale in relation to a scarce interrater reliability, this may be related to several different factors not assessed in the current study. For example, station duration has been reported to affect performance assessment reliability [13, 37]. Moreover, the same interpretation of the terminology used by a given instrument can play a role when adequate agreement of the empirical indicators in relation with the underlying concepts is not met between reviewers [38, 39]. Finally, we pointed out that no unanimous consensus exists when it comes to preferences for global rating scales for CS vs. more complex behavioural checklists [13, 14, 16, 17]. Although brief instruments may less likely fail to meet psychometric standards for comparability due to the shorter number of parameters to estimate, it remains an open question whether these competencies can be assessed by a unique scale across different specialties and practice conditions [40]. As suggested by Setyonugroho et al. [13] and Cömert et al. [14], in addition to investing on the standardisation and evaluation of CS' assessment tools, medical schools should match any measure of CS with how this concept is taught along their undergraduate and postgraduate training programs.

In sum, while our results evidence the limitations of this four-item global scale for CS in terms of comparability across stations and discriminant ability between students, in accordance with previous research [41], it showed good reliability results within OSCE stations. Accordingly, the joint use of measurement invariance techniques and IRT provide knowledge to improve its adoption in future assessments.

\section{Limitations and future research}

The major limitations of the current study are related to the items' scores averaging across stations posing a threat to the IRT's assumptions of unidimensionality and local independence, and the relatively small sample size. In fact, although the analyses were run on the original items' scores for testing the measurement invariance across OSCE stations, an approximation had to be done for the use of the IRT in order to maximise the available data and obtain a sample size closer to what is considered acceptable for Rasch modeling [24]. On a related note, De Champlain [42] pointed out that IRT might not be particularly well suited to OSCEs since students' performances on the same skills may vary across different stations' domains covering specific clinical skills. Future studies may thus adopt this type of analytical approach to estimate items' performances in single OSCE stations or clinical scenarios, provided that they have adequate sample sizes. For what concerns sample size, this was linked to the retrospective nature of the study can certainly been overcome in future research. Although recommendations about adequate sample size in the context of factor analysis vary from as low as 5 cases per estimated parameter [43], to 10 [44] or 20 [33], it has also been shown how sample size does not significantly affect hypotheses testing of measurement invariance [45]. Finally, future studies can be designed for examining how the set of items analysed here may vary in their measurement invariance properties across examiners grouped by specific characteristics (e.g., gender, specialty, OSCE evaluating experience).

\section{Conclusions}

The current study showed the advantages of adopting statistical approaches such as multi-group factorial analysis and IRT to evaluate a global rating scale for assessing CS among undergraduate medical students during OSCE. Our results and approach may help medical educators to normalize efforts across settings and institutions and create guidelines for the evaluation and adoption of measurement instruments for CS such as the one tested here. As pointed out by previous research [35, 36, 42, 46-49], analytical approaches such as IRT modeling can prove to be very useful in medical education especially for what concerning performance-based assessments. On the basis of this type of analysis, medical schools can support continuous evaluations of their assessment tools so to evidence where to improve them and propose new best-practices from evidence-based research.

\section{Additional file}

Additional file 1: Table A1. Descriptive statistics at the item-level for the communication scale by OSCE stations. Table A2. Results of the four-item communication scale measurement invariance testing across examination groups

\section{Acknowledgements}

Not applicable.

Authors' contributions

GP, BC: Conception and design, data analysis and interpretation, drafting the article, critical revision of the article and final approval. NJP: Conception and 
design, drafting the article, critical revision of the article and final approval. All authors have read and approved the manuscript.

\section{Funding}

The authors report no external funding source for this study.

\section{Availability of data and materials}

The datasets generated and/or analysed during the current study are not publicly available due to the privacy of the students but are available from the corresponding author on reasonable request.

\section{Ethics approval and consent to participate}

The Chair of the Cantonal Commission for Ethical Research (CCER) designated the current study as exempted from formal review (Req-201900946). Moreover, in consideration of the retrospective nature of the study and the anonymization of the data making impossible to identify any individual or small subgroup of students, the teaching committee (Bureau de la Commission d'Enseignement) approved the project study without the need of informed consent.

\section{Consent for publication}

Consent to publish is also not applicable.

\section{Competing interests}

The authors declare that they have no competing interests.

\section{Author details}

'Division of Primary Care, Population Epidemiology Unit, Geneva University Hospitals, Geneva, Switzerland. ${ }^{2}$ Institute of Public Health, Faculty of BioMedical Sciences, Università della Svizzera Italiana, Lugano, Switzerland. ${ }^{3}$ Faculty of Medicine, Unit of Development and Research in Medical Education (UDREM), University of Geneva, Geneva, Switzerland. ${ }^{4}$ Institute of Primary Care, Geneva University Hospitals, Geneva, Switzerland.

\section{Received: 1 October 2019 Accepted: 9 February 2021}

\section{Published online: 16 February 2021}

\section{References}

1. Zolnierek KBH, DiMatteo MR. Physician communication and patient adherence to treatment: a meta-analysis. Med Care. 2009;47(8):826.

2. Street RL Jr, Makoul G, Arora NK, Epstein RM. How does communication heal? Pathways linking clinician-patient communication to health outcomes. Patient Educ Couns. 2009;74(3):295-301.

3. Stewart MA. Effective physician-patient communication and health outcomes: a review. CMAJ. 1995;152(9):1423.

4. Frank J, Snell L, Sherbino J. The draft CanMEDS 2015 physician competency framework-series IV. Ottawa: The Royal College of Physicians and Surgeons of Canada; 2014

5. Council GM. Tomorrow's doctors: outcomes and standards for undergraduate medical education. Manchester: General Medical Council; 2009.

6. Lindgren S. Basic medical education WFME global standards for quality improvement. Denmark: World Federation for Medical Education; 2015.

7. Deveugele M, Derese A, De Maesschalck S, Willems S, Van Driel M, De Maeseneer J. Teaching communication skills to medical students, a challenge in the curriculum? Patient Educ Couns. 2005;58(3):265-70.

8. Hausberg MC, Hergert A, Kröger C, Bullinger M, Rose M, Andreas S. Enhancing medical students' communication skills: development and evaluation of an undergraduate training program. BMC Med Educ. 2012 $12(1): 16$.

9. Cegala DJ, Lenzmeier Broz S. Physician communication skills training: a review of theoretical backgrounds, objectives and skills. Med Educ. 2002; 36(11):1004-16.

10. Harden R, Stevenson M, Downie WW, Wilson G. Assessment of clinical competence using objective structured examination. Br Med J. 1975;1(5955): 447-51

11. Turner JL, Dankoski ME. Objective structured clinical exams: a critical review. Fam Med. 2008:40(8):574-8.

12. Baig LA, Violato C, Crutcher RA. Assessing clinical communication skills in physicians: are the skills context specific or generalizable. BMC Med Educ. 2009;9(1):22
13. Setyonugroho W, Kennedy KM, Kropmans TJ. Reliability and validity of OSCE checklists used to assess the communication skills of undergraduate medical students: a systematic review. Patient Educ Couns. 2015;98(12): 1482-91.

14. Cömert M, Zill JM, Christalle E, Dirmaier J, Härter M, Scholl I. Assessing communication skills of medical students in objective structured clinical examinations (OSCE)-a systematic review of rating scales. PLoS One. 2016; 11(3):e0152717.

15. Chang A, Boscardin C, Chou CL, Loeser H, Hauer KE. Predicting failing performance on a standardized patient clinical performance examination: the importance of communication and professionalism skills deficits. Acad Med. 2009;84(10):S101-4

16. Boon H, Stewart M. Patient-physician communication assessment instruments:: 1986 to 1996 in review. Patient Educ Couns. 1998;35(3):161-76.

17. Ilgen JS, Ma IW, Hatala R, Cook DA. A systematic review of validity evidence for checklists versus global rating scales in simulation-based assessment. Med Educ. 2015;49(2):161-73.

18. Steinmetz H, Schmidt $P$, Tina-Booh A, Wieczorek S, Schwartz SH. Testing measurement invariance using multigroup CFA: differences between educational groups in human values measurement. Qual Quant. 2009;43(4): 599-616.

19. Vandenberg RJ, Lance CE. A review and synthesis of the measurement invariance literature: suggestions, practices, and recommendations for organizational research. Organ Res Methods. 2000;3(1):4-70.

20. Hodges B, Mcllroy JH. Analytic global OSCE ratings are sensitive to level of training. Med Educ. 2003;37(11):1012-6.

21. LeBlanc VR, Tabak D, Kneebone R, Nestel D, MacRae H, Moulton C-A. Psychometric properties of an integrated assessment of technical and communication skills. Am J Surg. 2009;197(1):96-101.

22. Jefferies A, Simmons B, Tabak D, Mcilroy JH, Lee K-S, Roukema H, Skidmore M. Using an objective structured clinical examination (OSCE) to assess multiple physician competencies in postgraduate training. Med Teach. 2007; 29(2-3):183-91.

23. Scheffer S, Muehlinghaus I, Froehmel A, Ortwein H. Assessing students' communication skills: validation of a global rating. Adv Health Sci Educ. 2008;13(5):583-92.

24. Hambleton RK, Swaminathan H: Item response theory: principles and applications: Springer Science \& Business Media; 2013.

25. Monti M, Klöckner-Cronauer C, Hautz SC, Schnabel KP, Breckwoldt J, JunodPerron N, Feller S, Bonvin R, Huwendiek S. Improving the assessment of communication competencies in a national licensing OSCE: lessons learned from an experts' symposium. BMC Med Educ. 2020;20:1-7.

26. Peterson RA. A meta-analysis of variance accounted for and factor loadings in exploratory factor analysis. Mark Lett. 2000;11(3):261-75.

27. Cerny BA, Kaiser HF. A study of a measure of sampling adequacy for factoranalytic correlation matrices. Multivar Behav Res. 1977;12(1):43-7.

28. Gliem JA, Gliem RR: Calculating, interpreting, and reporting Cronbach's alpha reliability coefficient for Likert-type scales. In: 2003: Midwest Research-toPractice Conference in Adult, Continuing, and Community Education; 2003.

29. Chen FF. Sensitivity of goodness of fit indexes to lack of measurement invariance. Struct Equ Model. 2007;14(3):464-504.

30. Samejima F. Graded response model. In: Kempf-Leonard K, editor Encyclopedia of Social Measurement. New York: Academic Press; 2004. p. $77-82$.

31. Hays RD, Morales LS, Reise SP. Item response theory and health outcomes measurement in the 21st century. Med Care. 2000;38(9 Suppl):II28.

32. Van Der Linden WJ, Hambleton RK. Item response theory: Brief history, common models, and extensions. In: Van Der Linden WJ, Hambleton RK, editors. Handbook of modern item response theory. New York: Springer; 1997. p. $1-28$

33. Kline RB. Principles and practice of structural equation modeling. London: Guilford publications; 2015

34. Byrne BM, Shavelson RJ, Muthén B. Testing for the equivalence of factor covariance and mean structures: the issue of partial measurement invariance. Psychol Bull. 1989;105(3):456-66.

35. McManus IC, Thompson M, Mollon J. Assessment of examiner leniency and stringency ('hawk-dove effect') in the MRCP (UK) clinical examination (PACE S) using multi-facet Rasch modelling. BMC Med Educ. 2006;6(1):42.

36. Iramaneerat C, Yudkowsky R, Myford CM, Downing SM. Quality control of an OSCE using generalizability theory and many-faceted Rasch measurement. Adv Health Sci Educ. 2008;13(4):479. 
37. Patrício MF, Julião M, Fareleira F, Carneiro AV. Is the OSCE a feasible tool to assess competencies in undergraduate medical education? Med Teach. 2013;35(6):503-14.

38. Beckman TJ, Ghosh AK, Cook DA, Erwin PJ, Mandrekar JN. How reliable are assessments of clinical teaching? J Gen Intern Med. 2004;19(9):971-7.

39. Beckman TJ, Cook DA, Mandrekar JN. What is the validity evidence for assessments of clinical teaching? J Gen Intern Med. 2005;20(12):1159-64

40. Bloch $\mathrm{R}$, Norman $\mathrm{G}$. Generalizability theory for the perplexed: a practical introduction and guide: AMEE guide no. 68. Med Teach. 2012;34(11):960-92.

41. Ahrweiler F, Neumann M, Goldblatt H, Hahn EG, Scheffer C. Determinants of physician empathy during medical education: hypothetical conclusions from an exploratory qualitative survey of practicing physicians. BMC Med Educ. 2014;14(1):122.

42. De Champlain AF. A primer on classical test theory and item response theory for assessments in medical education. Med Educ. 2010:44(1):109-17.

43. Bentler PM, Chou C-P. Practical issues in structural modeling. Sociol Methods Res. 1987:16(1):78-117.

44. Schreiber JB, Nora A, Stage FK, Barlow EA, King J. Reporting structural equation modeling and confirmatory factor analysis results: a review. J Educ Res. 2006;99(6):323-38.

45. Koh KH, Zumbo BD. Multi-group confirmatory factor analysis for testing measurement invariance in mixed item format data. J Mod Appl Stat Methods. 2008;7(2):12.

46. Tavakol M, Dennick R. Post-examination analysis of objective tests. Med Teach. 2011;33(6):447-58

47. Bartman I, Smee S, Roy M. A method for identifying extreme OSCE examiners. Clin Teach. 2013;10(1):27-31.

48. Downing SM. Item response theory: applications of modern test theory in medical education. Med Educ. 2003;37(8):739-45.

49. Schauber SK, Hecht M, Nouns ZM. Why assessment in medical education needs a solid foundation in modern test theory. Adv Health Sci Educ. 2018; 23(1):217-32.

\section{Publisher's Note}

Springer Nature remains neutral with regard to jurisdictional claims in published maps and institutional affiliations.

Ready to submit your research? Choose BMC and benefit from:

- fast, convenient online submission

- thorough peer review by experienced researchers in your field

- rapid publication on acceptance

- support for research data, including large and complex data types

- gold Open Access which fosters wider collaboration and increased citations

- maximum visibility for your research: over $100 \mathrm{M}$ website views per year

At $\mathrm{BMC}$, research is always in progress.

Learn more biomedcentral.com/submissions 